\title{
Nonlinear Static Analysis by Finite Elements of a Fujian Hakka Tulou
}

\author{
Bruno Briseghella \\ University of Fuzhou, China \\ Valeria Colasanti, Luigi Fenu \\ University of Cagliari, Italy
}

\author{
Camillo Nuti \\ University of Roma Tre, Italy
}

\author{
Enrico Spacone \\ University of Chieti-Pescara, Italy
}

\author{
Humberto Varum \\ University of Porto, Portugal
}

Contacting author: Ifenu@unica.it

\begin{abstract}
Hakka Tulous are massive circular earth constructions of the Fujian Province, China, included in the UNESCO World Heritage list. They are subjected to earthquakes of medium magnitude, but their response to the seismic action is not yet investigated in depth. The seismic response of Fujian Tulous was herein investigated through pushover analysis modelling the Tulou structure by finite elements. Although the Tulou is a big construction with a circular earth wall of about fifty meters in diameter, a micromechanical approach was used to model the earth nonlinear behaviour. Even if no binder is added to the earthen material, the Concrete Damaged Plasticity model can be adopted and has shown to be effective in modelling its nonlinear behaviour, as well as the nonlinear response of the Tulou earth wall. Performing pushover analysis of a big earth structure using a micromechanical approach seems to give reliable results, that must be proved by future research.

Keywords: Hakka Tulou; seismic response; non-linear static analysis; finite elements; Concrete Damage Plasticity model; Capacity cure.
\end{abstract}

\section{Introduction}

Hakka Tulous are big circular earth constructions typical of the Fujian Province, China. They are very important by both a cultural and architectural point of view and, for this reason, included in the UNESCO World Heritage list. 
In recent years there is an increasing interest in earth constructions for two main reasons:

- many of them, like Tulous, are part of the cultural heritage of a number of countries all over the world [1-3];

- they are a very good example of sustainable constructions, because little energy is required not only to build, but also to heat and refresh them, comfort is high, and the building material is wholly recyclable and available on (or not far from) the construction site $[4,5]$.

For all these reasons, lot of research has been done on restoration and conservation of old earth constructions [6,7], as well as on new earth buildings [8-16] and on the earthen material [1724].

Few studies have been done on the seismic response of earth constructions. Recent studies have faced the problem of modelling the response of earth constructions by finite elements [14-16]. Several authors have studied the earthquake damage in existing earth buildings and their seismic vulnerability $[6,25]$. The earthquake response of earth buildings has been investigated through experimental tests on housing structures and on structural elements $[8,9,23,24,26-28]$.

The Tulous' seismic response is furthermore not sufficiently known. Although in the Fujian Province the earthquake hazard is not high, the Tulous are subjected to a seismic action of medium magnitude, that could be a threat for constructions in low-strength material where hundreds of people live together [29].

Moreover, the literature on the seismic response

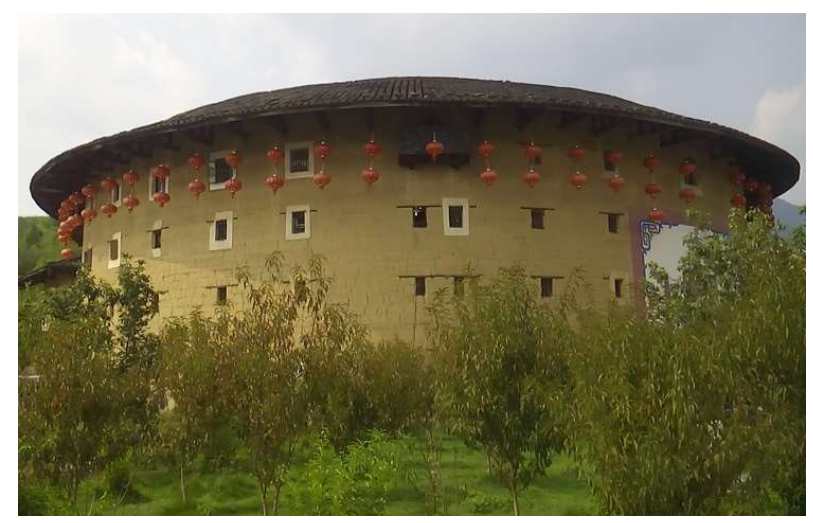

(a) of Tulous is practically absent, even if the authors of this study have started research on this topic by studying the overall seismic response of Tulous through modelling them by macroelements [30].

In this paper nonlinear static analysis (pushover) is used to investigate the seismic response of Fujian Tulous modelled by finite elements. Although a Tulou is a big construction with a circular wall of about fifty meters in diameter, a micromechanical approach is used. This is favoured by the construction technique (pisé), consisting in erecting the earth wall through pouring the wet earthen material into a formwork and compact it through ramming. The pisé is in fact also known as rammed earth [31].

The construction technique allows to obtain a nearly isotropic material. This is a great advantage to use a micromechanical approach to model such a big earth construction. The complex nonlinear behaviour of the earthen material was modelled through the Concrete Damaged Plasticity (CDP) model [32-35] that has shown to be effective for this aim.

CDP allows to model the material behaviour until a high damage level is attained. For high damage level (> 85\%), high deformations occur, thus describing a cracking pattern.

Pushover analysis was performed by applying the horizontal inertial forces as a percentage of the gravity forces, and by detecting the displacement of a suitably chosen control node. The total shear force as a function of the displacement of the control node was plotted. The nonlinear model was able to plot the curve until damage caused a

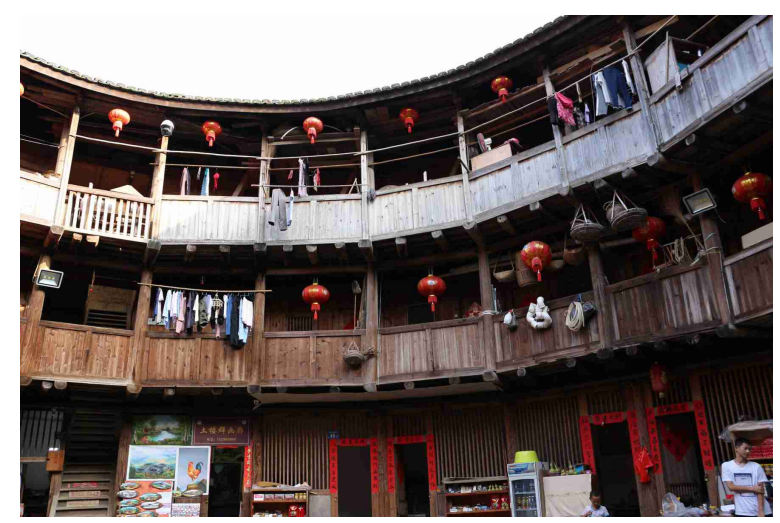

(b)

Figure 1. Hakka Tulou in Fujian Province. External view (a) and internal view (b). 
significant loss of the load bearing capacity of the structure.

\section{Description of a Fujian Hakka Tulou}

A circular Tulou consists of a big circular earth wall erected through the pisé technique, and of an inner wood structure made of 3D frames stiffening the earth wall (Figure 1a). Timber beams in the radial direction, supported by the earth wall and by timber columns at their opposite ends, in turn support timber floors made of wooden rafters and planks (Figure 1b). A circular timber gable roof significantly cantilevering out externally from the earth wall and internally from the wood floors protects the Tulou from the heavy rains of the typhoons that frequently occur in the Fujian Province.

Along the circular earth wall, one entrance door only allows to enter into the Tulou, in a large internal courtyard limited by the main big circular building above described. The courtyard is often free from other constructions, otherwise inside the courtyard there are some minor earth buildings.

Hundreds of Hakka people of the same clan live in each Tulou in dwellings supported by the wooden floors and positioned along the Tulou circumference.

\section{Nonlinear modelling of the Tulou by Finite Elements}

\subsection{Description of the modelled structure}

The structure under investigation is not exactly a Tulou but is very similar to it. In particular, its geometry is the same of a Tulou prototype recently studied by Briseghella et al. [30] , except for the roof and for the window size. For the sake of simplicity it has a floor roof totally similar to the other timber floors instead of the typical gable roof of Fujian Tulous. Also, the window size was higher than that usually adopted in real Tulous, because too small windows define too small piers and lintels. This choice was made because the aim of this research is to also investigate the response under horizontal actions of piers and lintels of a circular wall, as well of the nodes connecting them. For this reason, a window size more similar to that generally adopted in masonry constructions was preferred.

In so doing, on the one hand comparison with the response of plane walls with current opening size can be made. On the other hand, in implementing a nonlinear model of a real Tulou with small windows, the same modelling problems are faced. This allowed to first have solved the problem of implementing a nonlinear $\mathrm{FE}$ model of a big circular earth structure with a micromechanical approach as well as to have a numerical model ready to be easily modified to become the model of a Tulou.

\subsection{Numerical model}

An earth construction made of a circular earth wall internally stiffened by wooden frames supporting four circular wooden floors and subjected to the seismic action was modelled (Figure 2). While it seemed reasonable to consider wooden frames and floors to behave linearly, the nonlinear response of the earthen material was to be considered. For this aim, the Concrete Damaged Plasticity (CDP) model was adopted, meaning that a micromechanical approach was used. Usually, this approach is successfully adopted for local models owing to the difficulties in achieving convergence and the high computation time required. Nevertheless, since the circular wall of a Tulou is a masonry structure made of only pisé, and the pisé can be practically considered as an isotropic material, then the micromechanical approach was tried using finite elements with side of about $50 \mathrm{~cm}$, that are

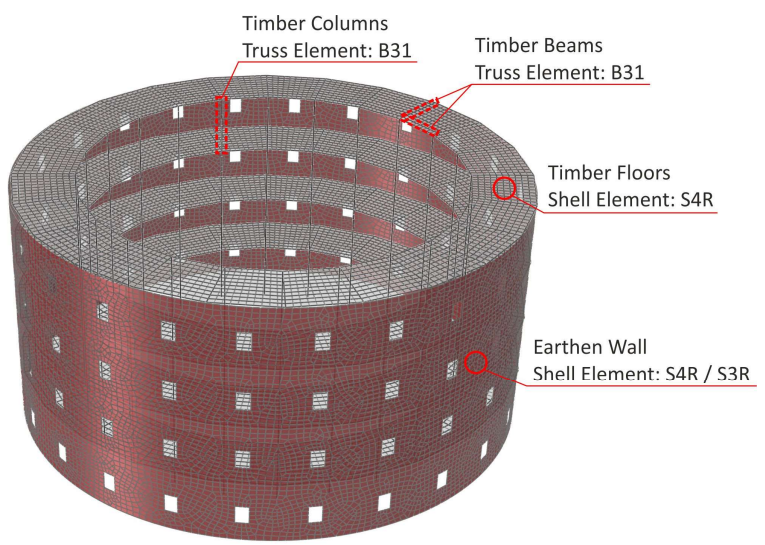

Figure 2. Model of the analysed earth construction. 
however quite small for a wall of about $50 \mathrm{~m}$ in diameter and $20 \mathrm{~m}$ in height.

Since the nonlinear analysis with CDP is hard to converge especially in a big structure, nonlinear $\mathrm{FE}$ analysis was carried out in Abaqus/Explicit. Both the circular earth wall and the diaphragms of the wooden floors were modelled using general purpose shell elements with 3 and 4-nodes, (respectively, elements S3R and S4R available in Abaqus software) reduced integration, and hourglass control (Figure 2). Beams and columns of the wooden frames were modelled with 2-node linear beam elements (B31 in Abaqus) (Figure 2).

\subsubsection{Material modelling}

In the linear elastic range, Young's modulus $E_{0}=1000 \mathrm{MPa}$ and Poisson's ratio $\nu=0.2$ were assumed. At failure, compressive and tensile strength $f_{c}=1 \mathrm{MPa}$ and $f_{t}=0.56 \mathrm{MPa}$, respectively. were also assumed. Unit weight of $16 \mathrm{kN} / \mathrm{m}^{2}$ was taken. There is few literature on the mechanical properties of the Tulou earthen material. Only its unit weight and compressive strength were deduced from some mechanical tests available in the literature [36], while the other mechanical properties are presumed from mechanical tests on similar earthen materials reported in the literature [22].

The CDP model assumes that failure is achieved for tensile cracking or compressive crushing, and that damaged elasticity is combined with isotropic tensile and compressive plasticity. This means that beyond the first cracking point, for increasing strains, plasticity occurs with increasingly damaged elasticity, that is with a decrease of the elastic modulus after an unloading-reloading cycle. Damage functions in tension $d_{t}$ and in compression $d_{c}$ are defined, so that, for each plastic strain level, the elastic moduli in tension and in compression are defined as $\left(1-d_{t}\right) E_{0}$ and (1$\left.d_{c}\right) E_{0}$, respectively (Figure $\left.3 a-b\right)$. Moreover, a nonassociated flow rule in accordance with DruckerPrager hyperbolic function is assumed. Some other parameters are then required:

- Dilation angle: the angle between the hydrostatic axis and the yield function in a meridian plane. The value of $30^{\circ}$ was adopted [37];

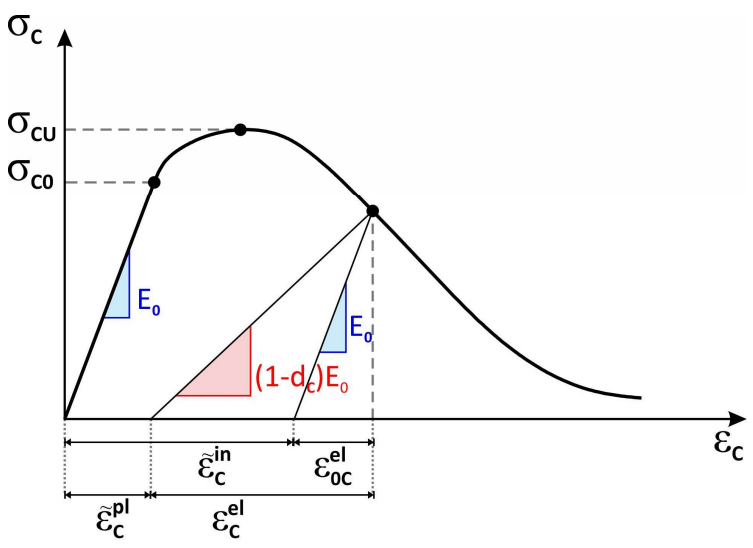

(a)

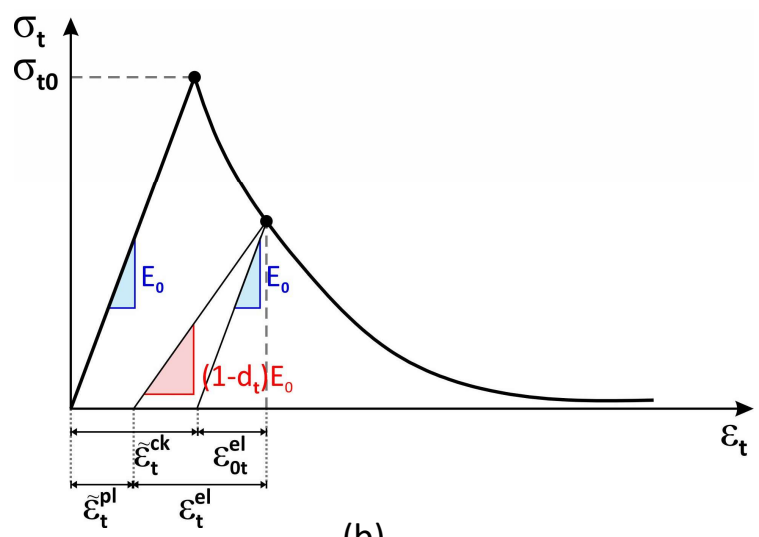

(b)

Figure 3. Behaviour of quasi-brittle materials under uniaxial compression (a) and uniaxial tension (b).

- Eccentricity: a small positive constant defining the rate at which the hyperbole potential function approaches its asymptote. The default value of 0.1 was used [37] ;

- $\sigma_{\mathrm{bo}} / \sigma_{\mathrm{c} 0}$ : the ratio of the strength in the biaxial state over the strength in the uniaxial state. According to the experimental results reported by Kupfer et al. [38], the Abaqus default value 1.16 was assumed [37];

- $K_{c}$ : the ratio of the distance of the hydrostatic axis from the compressive meridian over that from the tensile meridian in a deviatoric cross plan. The default value 0.667 suggested in Abaqus was assumed [37];

- Also, the rate of convergence was increased by slightly modifying the constitutive laws through viscosity regularization. 


\section{Results from Nonlinear Static Analysis by Finite Elements}

In this research the seismic response of circular earth structures and in particular of Hakka Tulous is studied. Nonlinear static analysis (pushover) is an important tool for this aim because is able to take into account the energy dissipation allowed by material nonlinearity.

In this paper pushover analysis was performed by finite elements by increasingly applying the horizontal seismic action as an inertial force.

Since static analysis was performed, then the d'Alambert forces should be assumed to be zero, and typically this problem would be solved with Abaqus/Standard. Nevertheless, the difficulty in achieving convergence due to the complexity of the material modelling instead suggested to use Abaqus/Explicit. It suitably introduces small d'Alambert forces causing a perturbation of the equilibrium equations that allows the algorithm to achieve convergence.

The explicit procedure can often allow to achieve convergence quickly, but with unreliable results. Too high perturbation of the equilibrium equations can in fact affect the reliability of the results, meaning that convergence is achieved but with too high d'Alambert forces, not present in the problem under consideration.

In this specific case, the results appear not to be significantly affected by the dynamic perturbation caused by the low d'Alembert forces applied in the explicit procedure. This is shown by the plots in Figure 4, where the external and internal energy vary slowly and practically merge at any deformation level. It means that the external and internal energy have practically the same value during the pushover analysis, and that the total energy is practically zero (Figure 4).

The capacity curve of the Tulou was obtained through nonlinear static analysis performed by finite elements. The CDP model has allowed to obtain the capacity curve of the structure through exploiting the post-peak deformations of the Tulou earth wall, whose circular form is suited to resist the seismic action. The capacity curve shows that failure occurred with a loss of $25 \%$ of load bearing capacity and a capacity displacement of $13 \mathrm{~cm}$ (Figure 5). The CDP model has shown to effectively simulate the nonlinear response of the

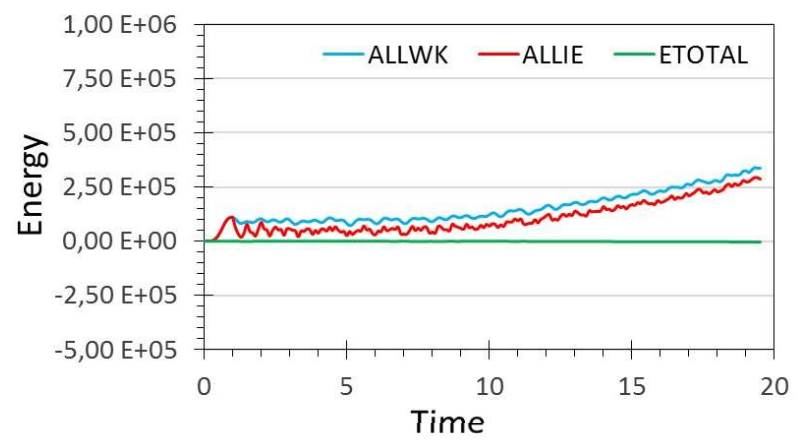

Figure 4. Energy balance during the analysis: internal energy (ALLIE), external energy (ALLWK) and total energy (ETOTAL).

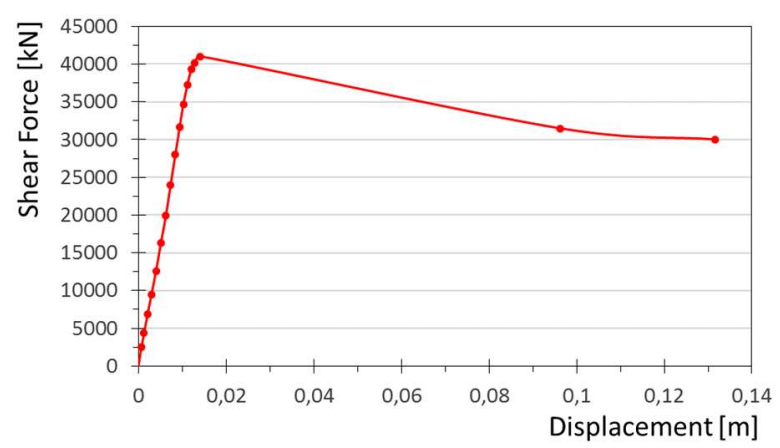

Figure 5. Capacity curve of the analysed earth construction.

earthen material. These values of course depend on the material properties of the earthen material, and in particular by its tensile strength and fracture energy. Since they are not available for the rammed earth of the Tulou, their values were obtained by the literature [22]. Therefore the effective value of the capacity displacement can be reliably calculated only when the effective material properties of the Tulou earthen material will be obtained by testing.

Nonlinear FEA has shown that failure of the Tulou wall occurred close to its base (Figure 6), in accordance with the results obtained by modelling the Tulou wall by macroelements [30]. In particular shear was shown to occur in the wall regions almost parallel to the seismic action $(Y$ direction in Figure 7a) while normal stresses in the horizontal and in the vertical direction (S11 and S22, respectively) occurred in wall regions almost 
orthogonal to the seismic action (Figure $7 b-c$ ).

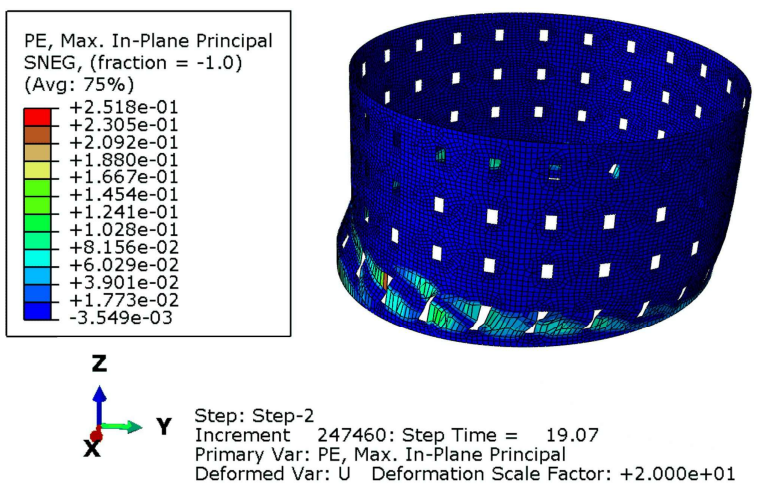

Figure 6. Plastic strains and displaced shape at failure for $Y$ direction of the seismic action.
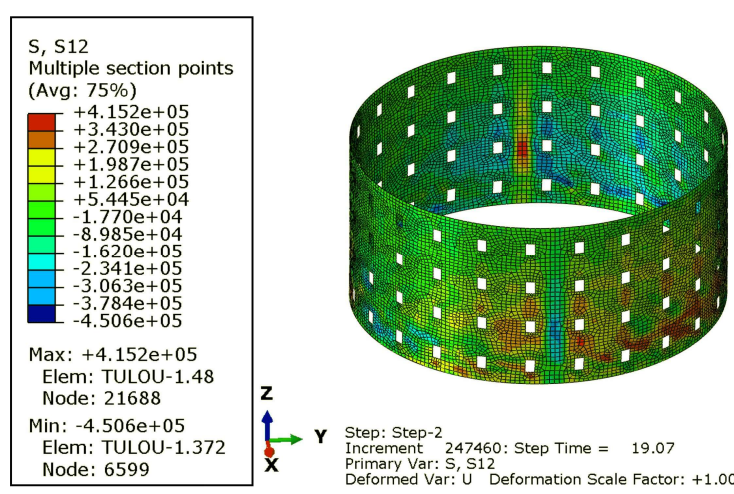

(a)

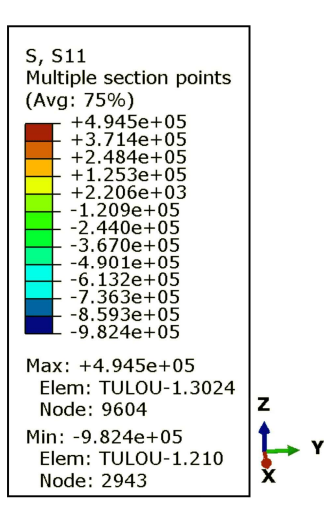

Step: Step-2
Increment 247460: Step Time $=19.07$
Primary Var: S, S12

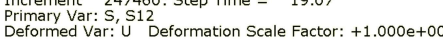

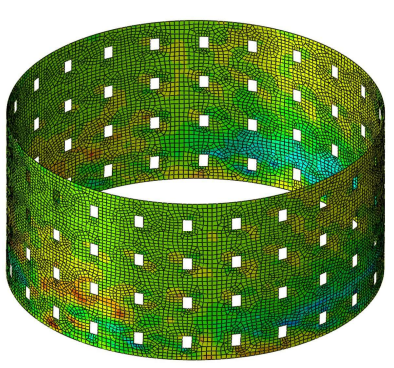

(b)

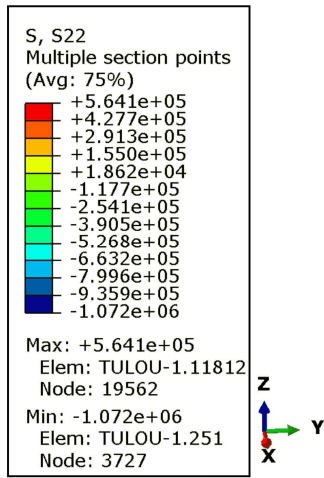

Step: Step-2
Increment 247460: Step Time $=19.07$
Primary Var: S S11

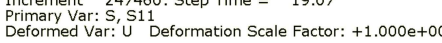

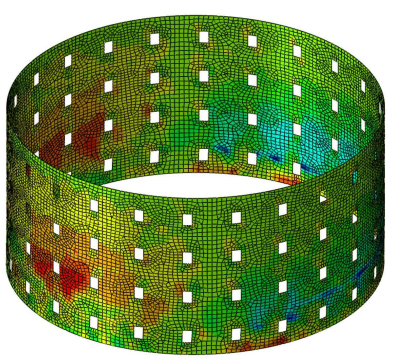

(c)

Figure 7. In-plane stresses in the circular earth wall: shear stresses (a), normal stresses in the vertical direction (b) and in the horizontal direction (c).
These first results need confirmation by future research.

\section{Conclusions}

This paper deals with the seismic analysis of Hakka Tulous, typical earth buildings of the architectural heritage of the Fujian Province (China), which are included in the UNESCO World Heritage list.

To check the Tulou seismic resistance, a finite element model accounting for material nonlinearity was implemented. The earthen material was modelled through the Concrete Damaged Plasticity (CDP) model, that is actually effective in simulating the nonlinear response of quasi-brittle materials, including earth.

Nonlinear static analysis (pushover) was hence performed by finite elements using a micromechanical approach.

Although for convergence problems the accurate material modelling usually suggests to use the micromechanical approach only for local models, in the case of Tulous the material uniformity of the rammed earth (pisé) has allowed to extend the micromechanical approach to a whole big construction like a Tulou.

To achieve convergence, an explicit procedure was used, meaning that the equilibrium equations where slightly perturbed by suitably applying d'Alembert forces.

Reliable results were achieved. In particular, the algorithm was able to carry out pushover analysis for significantly high displacement values, thus allowing to obtain a reliable capacity curve of the structure. The results show that the nonlinear model is well able to take into account the earth masonry cracking. Moreover, it has been noted that failure occurred at the Tulou base with significant shear deformations. These results are in accordance with those achieved for a similar structure analysed by macroelements, but are to be confirmed by future research.

\section{Acknowledgements}

The research was supported by the Recruitment Program of Global Experts Foundation (Grant No. TM2012-27) and National Natural Science 
Foundation of China (Grant No. 51778148) and by the Sardinian Region funding LR N.7 07/08/2007 Year 2011 Tender 3 CRP-48693 and Year 2013 CRP-78176. The authors would also like to acknowledge the Sustainable and Innovative Bridge Engineering Research Center (SIBERC) of the College of Civil Engineering, Fuzhou University (Fuzhou, China), and the Department of Civil Engineering, Environmental Engineering and Architecture of the University of Cagliari (Cagliari, Italy).

\section{References}

[1] Silveira D, Varum H, Costa A. Rehabilitation of an important cultural and architectural heritage: the traditional adobe constructions in Aveiro district. Sustainable Development and Planning III. Southampton, UK: WIT Press; 2007. p. 705-714.

[2] Gandreau D, Delboy L. World heritage inventory of earthen architecture. CRATerreENSAG, Grenoble (France). 2012;

[3] Achenza MM. II manuale del recupero dell'architettura storica dell'oasi di Figuig (Marocco): criticità e buone pratiche. Universita'degli Studi di Cagliari; 2012.

[4] Houben H, Guillaud H. Earth Construction: A Comprehensive Guide. Publications IT (ed.) Intermediate Technology Publications; 1994.

[5] Minke G. Building with Earth: Design and Technology of a Sustainable Architecture. [Online] Basel - Berlin - Boston: Birkhäuser; 2007. 198 p.

[6] Blondet $\mathrm{M}$, Vargas J, Velásquez J, Tarque $\mathrm{N}$. Experimental Study of Synthetic Mesh Reinforcement of Historical Adobe Buildings. In: Lourenço PB, Roca P, Modena C, Agrawal S (eds.) Proceedings of Structural Analysis of Historical Constructions. New Delhi; 2006. p. 1-8.

[7] Varum H, Tarque N, Silveira D, Camata G, Lobo B, Blondet $\mathrm{M}$, et al. Structural Behaviour and Retrofitting of Adobe Masonry Buildings. In: Costa A, Guedes JM, Varum H (eds.) Structural Rehabilitation of Old Buildings. New York: Springer Berlin Heidelberg; 2014. p. 37-75.
[8] Tolles EL, Kimbro EE, Webster FA, Ginell WS. Seismic Stabilization of Historic Adobe Structures. 2000.

[9] Blondet M, Torrealva D, Garcia GV, Ginocchio $F$, Madueño I. Using industrial materials for the construction of safe adobe houses in seismic areas. Proceedings of Earthbuild 2005 Conference. Sydney; 2005. p. 76-90.

[10] Figueiredo A, Varum H, Costa A, Silveira D, Oliveira C. Seismic retrofitting solution of an adobe masonry wall. Materials and Structures. Springer Netherlands; 2013;46(12): 203-219.

[11] Liu T, Zordan T, Zhang Q, Briseghella B. Equivalent viscous damping of bilinear hysteretic oscillators. Journal of Structural Engineering. American Society of Civil Engineers; 2015;141(11): 6015002.

[12] Tareco H, Grangeia C, Varum H, Matias MS. A high resolution GPR experiment to characterize the internal structure of a damaged adobe wall. EAGE First Break. 2009;27(8): 79-84.

[13] Antunes $P$, Lima $H$, Varum $H$, André P. Optical fiber sensors for static and dynamic health monitoring of civil engineering infrastructures: Abode wall case study. Measurement. 2012;45(7): 1695-1705.

[14] Tarque N. Numerical modelling of the seismic behaviour of adobe buildings. Università degli Studi di Pavia; 2011.

[15] Tarque N, Camata G, Spacone E, Varum H, Blondet M. Nonlinear Dynamic Analysis of a Full-Scale Unreinforced Adobe Model. Earthquake Spectra. Earthquake Engineering Research Institute; 2013;30(4): 1643-1661.

[16] Tarque N, Camata G, Varum H, Spacone E, Blondet $\mathrm{M}$. Numerical simulation of an adobe wall under in-plane loading. Earthquakes and Structures. Techno-Press; 2014;6(6): 627646.

[17] Aymerich F, Fenu L, Francesconi L, Meloni P. Fracture behaviour of a fibre reinforced earthen material under static and impact flexural loading. Construction and Building Materials. Elsevier Ltd; 2016;109: 109-119. 
[18] Millogo $Y$, Hajjaji $M$, Ouedraogo R. Microstructure and physical properties of lime-clayey adobe bricks. Construction and Building Materials. 2008;22(12): 2386-2392.

[19] Crocker E. Earthen Architecture and Seismic Codes; Lessons From the Field. Proceedings of VIII International conference on structural studies, repairs and maintenance of heritage architecture. Halkidiki, Greece; 2003.

[20] Yetgin Ş, Çavdar Ö, Çavdar A. The effects of the fiber contents on the mechanic properties of the adobes. Construction and Building Materials. 2008;22(3): 222-227.

[21] Aymerich F, Fenu L, Meloni P. Effect of reinforcing wool fibres on fracture and energy absorption properties of an earthen material. Construction and Building Materials. 2012;27(1): 66-72.

[22] Parisi F, Asprone D, Fenu L, Prota A. Experimental characterization of Italian composite adobe bricks reinforced with straw fibers. Composite Structures. Elsevier Ltd; 2015;122: 300-307.

[23] Blondet M, Vargas J. Investigación sobre vivienda rural. 1978.

[24] Varum H, Costa A, Silveira D, Pereira H, Almeida J, Martins T. Structural Behaviour Assessment and Material Characterization of Traditional Adobe Constructions. Adobe USA. NNMC and Adobe Association of the Southwest. El Rito, NM; 2007.

[25] Webster FA, Leroy Tolles E. Earthquake damage to historic and older adobe buildings during the 1994 Northridge, California Earthquake. Proceedings of 12th World Conference on Earthquake Engineering. Auckland, New Zealand; 2000.

[26] Asprone D, Parisi F, Prota A, Fenu L, Colasanti V. Adobe in Sardinia. Static and dynamic behaviour of the earthen material and of adobe constructions. 16th International Brick \& Block Masonry Conference. Padova; 2016.

[27] Colasanti V. Il comportamento sismico delle costruzioni in terra cruda. Università degli Studi di Cagliari; 2016.
[28] Gavrilovic P, Sendova V, Ljubomir T, Krstevska L, Ginell WS, Tolles EL. Shaking Table Tests of Adobe Structures. 1996.

[29] Liang R, Stanislawski D, Hota G. Structural Responses of Hakka Rammed Earth Buildings under earthquake loads. International Workshop on Rammed Earth Materials and Sustainable Structures. Xiamen, China; 2011.

[30] Briseghella B, Colasanti V, Fenu L, Nuti C, Spacone E, Varum H. Seismic analysis by macroelements of circular earth constructions: the Fujian Tulou. In: DISS_Edition (ed.) Dynamic Interaction of Soil and Structure (DISS_17) - 5th International Workshop. Roma; 2017.

[31] Ciancio D, Beckett C. Rammed Earth Construction: Cutting-Edge Research on Traditional and Modern Rammed Earth. CRC Press; 2015.

[32] Lee J, Fenves GL. Plastic-Damage Model for Cyclic Loading of Concrete Structures. [Online] Journal of Engineering Mechanics. 1998. p. 892-899.

[33] Lubliner J, Oliver J, Oller S, Oñate E. A plasticdamage model for concrete. International Journal of Solids and Structures. 1989;25(3): 299-326.

[34] Modéer M. A fracture mechanics approach to failure analysis of concrete materials. Lund University of Technology, Sweden; 1979.

[35] Sümer $Y$, Aktaş M. Defining parameters for concrete damage plasticity model. Challenge Journal of Structural Mechanics. 2015;1(3): 149-155.

[36] Zhang PC, Luo K, Liao W Bin. Study on the Material and the Structure of Earth Building in Fujian. Advanced Materials Research. 2011;368-373: 3567-3570.

[37] Dassault Systemes Simulias Corp. Providence. ABAQUS Analysis User's Manual, versione 6.12. Rhode Island, USA; 2012.

[38] Kupfer H, Hilsdorf HK, Rusch H. Behavior of concrete under biaxial stresses. Journal proceedings. 1969. p. 656-666. 